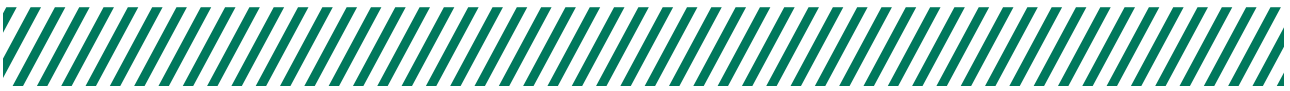

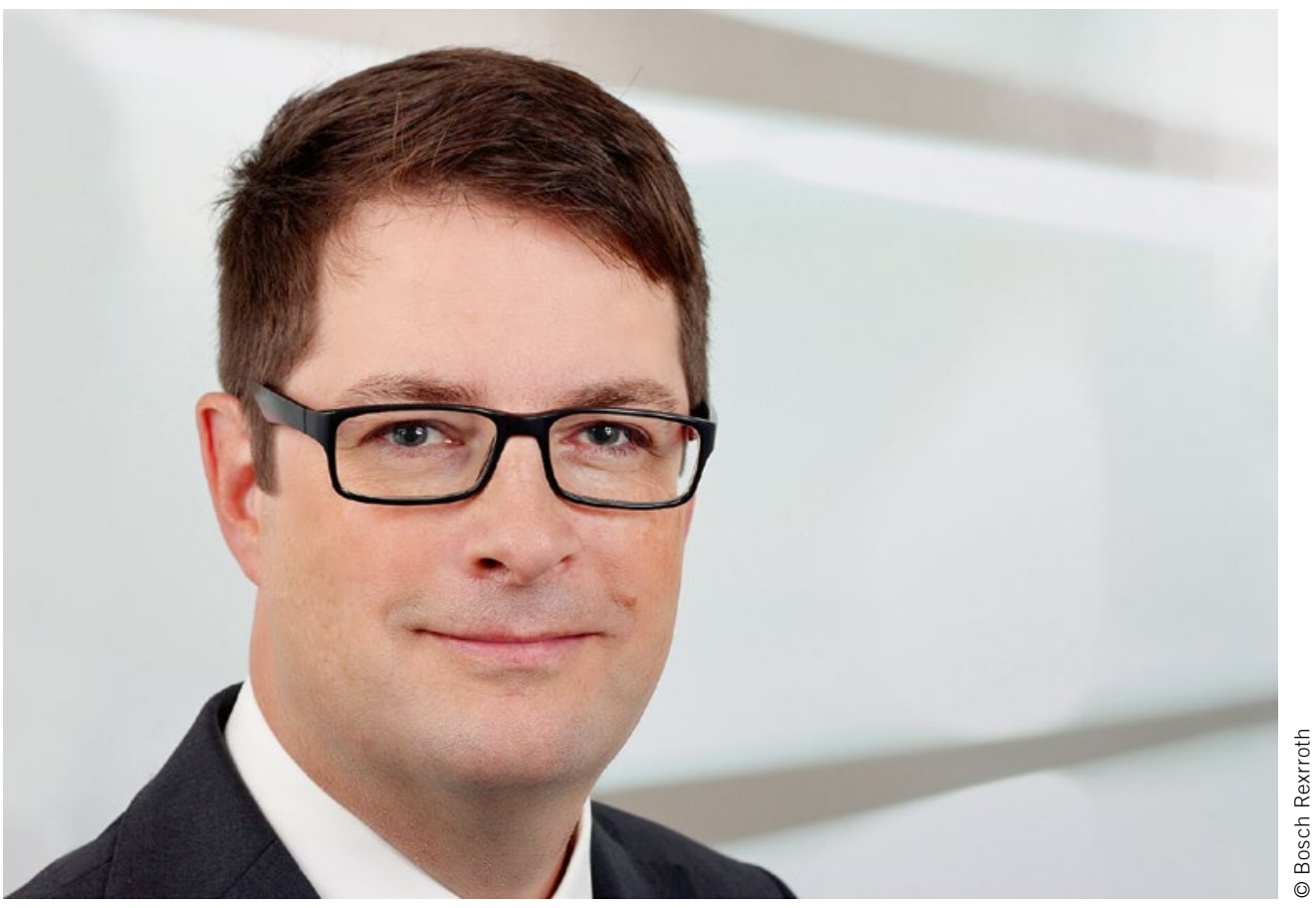

Dr. Alexander Flaig

Leiter Entwicklung Mobilelektronik und Systeme bei der Bosch

Rexroth $A G$ in Elchingen

\section{Trend zur Elektronifizierung in der Baumaschinenindustrie}

Der Trend zur Elektronifizierung bisher mechanischer oder hydraulischer Funktionen ist seit vielen Jahren in Landmaschinen zu beobachten. Zwei Haupttreiber dieses Trends sind die vielfältige Anpassbarkeit des Traktors als Universalmaschine an unterschiedliche Arbeitsaufgaben sowie der Druck zu besserer Energieeffizienz (die Kraftstoffkosten sind einer der höchsten Kostenblöcke der Landwirtschaft). In jüngster Zeit kommen Automatisierung und Vernetzung der Arbeitsprozessketten zur Steigerung der Produktivität als weitere Treiber hinzu.

Auch in der Baumaschine sind geringer Kraftstoffverbrauch und möglichst kompakte Motoren wichtig. Der Betrieb des Verbrennungsmotors mit optimalem Wirkungsgrad macht im Fahrantrieb die Entkoppelung von Fahrgeschwindigkeit und Motordrehzahl notwendig. Genau dies erreichen verschiedene Konzepte von CVT-Getrieben, die wiederum eine elektronische Ansteuerung erzwingen. Der Nachteil des geringen Stützmoments kleinvolumiger, hochaufgeladener Motoren beim Abbremsen wird ebenfalls elektronisch geregelt und über den Hydrostat im Antriebsstrang kompensiert. Schnelleres, dynamisches Fahren bei gleichzeitig reduziertem Kraftstoffverbrauch wird so möglich.

In der Arbeitshydraulik ist die Elektronifizierung bei ferngesteuerten Maschinenfunktionen (zum Beispiel Betonverteilermasten) oder automatisierten Arbeitsfunktionen (zum Beispiel
Straßenbaumaschinen) bereits umgesetzt. Bei Erdbewegungsmaschinen schließt jedoch der in der Regel hochausgebildete Fahrer durch die manuelle Betätigung der Arbeitshydraulik den Lageregelkreis. Durch den Druck zu höherer Produktivität bei gleichzeitig verringertem Energieverbrauch steigen aber auch die Anforderungen an den Fahrer. Eine jederzeit individuell auf den Fahrer und die spezifische Arbeit optimal adaptierbare Arbeitshydraulik setzt deren elektronische Steuerung voraus. Auf dieser Basis setzen Assistenzfunktionen, wie das automatisierte Planziehen, auf, die den Fahrer nachhaltig unterstützen und entlasten. Solche Funktionen kostengünstig mit einem Minimum an Sensorik abzubilden, stellt jedoch heute noch eine Herausforderung dar.

In vielen Maschinen sind Fahr- und Arbeitshydraulik gleichzeitig gefordert. Die hydraulische Abstimmung zwischen diesen beiden Systemen ist bereits auf einem sehr hohen Niveau und wird als Grundvoraussetzung gesehen. Die elektronische Antriebssteuerung bietet eine deutlich größere Flexibilität der Abstimmung. Das Maschinenverhalten hängt dann wesentlich von der Güte und Flexibilität der Parametrierung ab. Weitere Steigerungen der Maschinenperformance werden zukünftig auf Basis eines ganzheitlichen elektronischen Leistungsmanagements unter Einbezug des Verbrennungsmotors möglich. 